\title{
Experimental Investigation of Solar Panel Cooling by a Novel Micro Heat Pipe Array
}

\author{
Xiao Tang, Zhenhua Quan, Yaohua Zhao \\ Architectural and Civil Engineering Institute, Beijing University of Technology, Beijing, China \\ E-mail:yhzhao@bjut.edu.cn \\ Received April 8, 2010; revised May 24, 2010; accepted June 29, 2010
}

\begin{abstract}
A novel micro heat pipe array was used in solar panel cooling. Both of air-cooling and water-cooling conditions under nature convection condition were investigated in this paper. Compared with the ordinary solar panel, the maximum difference of the photoelectric conversion efficiency is $2.6 \%$, the temperature reduces maximally by $4.7^{\circ} \mathrm{C}$, the output power increases maximally by $8.4 \%$ for the solar panel with heat pipe using air-cooling, when the daily radiation value is $26.3 \mathrm{MJ}$. Compared with the solar panel with heat pipe using air-cooling, the maximum difference of the photoelectric conversion efficiency is $3 \%$, the temperature reduces maximally by $8^{\circ} \mathrm{C}$, the output power increases maximally by $13.9 \%$ for the solar panel with heat pipe using water-cooling, when the daily radiation value is $21.9 \mathrm{MJ}$.
\end{abstract}

Keywords: Solar Panel Cooling, Photoelectric Conversion Efficiency, Micro Heat Pipe array

\section{Introduction}

Solar cell is the core component of photovoltaic power generation system. The photoelectric conversion efficiency of a solar cell is about $6-15 \%$ in commercial application [1]. Most of the radiation has been converted into heat, which results in high temperature of the solar cell and low efficiency even inefficiency. According to Weng et al [2], the temperature increase of $1 \mathrm{~K}$ corresponds to the reduction of the photoelectric conversion efficiency by $0.2 \%-0.5 \%$. In addition, long-term high temperature of the solar cell will shorten its service life. Therefore, solar cell cooling is of essential importance.

Air-cooling and water-cooling methods are both commonly used in solar cell cooling [2-4]. Heat pipe cooling is deemed to be a promising cooling technology [5-7]. Moreover, there are large thermal contact resistance existing between conventional column heat pipe and flat solar panel, which will results in low heat transfer efficiency. The novel micro heat pipe array proposed by Zhao et al. $[8,9]$ has a good contact with the solar panel, as its flat shape. And the heat pipe has higher heat transfer efficiency and a uniform temperature distribution that can solve the solar panel cooling issue.

\section{Experimental Setup and Scheme}

The heat pipe consisted of two sections, evaporator sec- tion and condenser section. The input heat vaporized the liquid inside the evaporator section, transfer to the condenser section. The condenser section is cooled by air or water. Hence, the heat pipe can transfers the heat from solar panel to air or water, to reduces the temperature of the solar panel and improve the photoelectric conversion efficiency.

\subsection{Experimental Setup}

A silicon solar panel was used in this experiment, with its peak efficiency in the range of $10-15 \%$ under standard condition $\left(25^{\circ} \mathrm{C}, 1000 \mathrm{~W} / \mathrm{m}^{2}\right)$, peak power of $10 \mathrm{~W}$ and an area of $0.0625 \mathrm{~m}^{2}$.

The cooling setup is schematically shown in Figure 1, which was setting up outdoor. The solar panel should face the south with a tilt angle of $45^{\circ}$ [10]. Its total radiation area was $0.2049 \mathrm{~m}^{2}$. The air-cooling solar panel is shown in Figure 1(a). The evaporator section of the heat pipe was adhered to the back of the solar panel with its length of $283 \mathrm{~mm}$ and width of $300 \mathrm{~mm}$. The condenser section was exposed to the air with its length of $200 \mathrm{~mm}$ and width of $300 \mathrm{~mm}$. The schematic of the water-cooling solar panels is shown in Figure 1(b), the evaporator section of the heat pipe was adhered to the back of the solar panel with its length of $283 \mathrm{~mm}$ and width of $285 \mathrm{~mm}$. The condenser section was adhered to a water flume with its length of $40 \mathrm{~mm}$ and width of $285 \mathrm{~mm}$. The specs of 


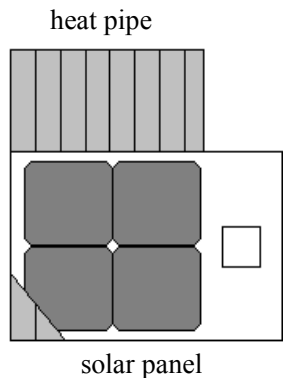

(a) Air-cooled with heat pipe

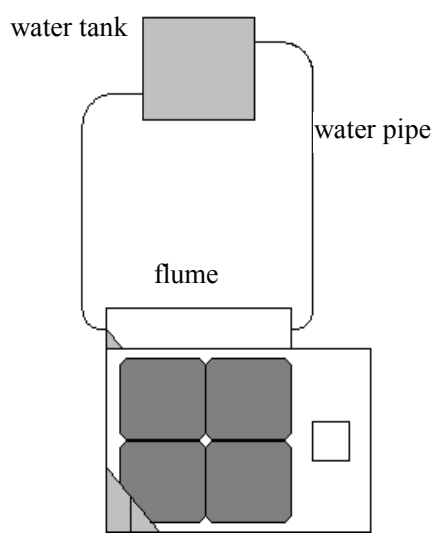

(b) Water-cooled with heat pipe

Figure 1. Cooling systems of solar panels.

water flume and water tank are $40 \times 25 \times 385 \mathrm{~mm}$ and $280 \times 280 \times 280 \mathrm{~mm}$, respectively. There is a distance of $170 \mathrm{~mm}$ between them.

\subsection{Experimental Scheme}

In order to discuss the main factors of the solar panel, the following parameters should be measured, such as the output power, the surface temperature and the photoelectric conversion efficiency.

1) Power output characteristics: Resistive load two -terminal test method was adopted, due to the small output current of the solar panel [11]. The test system is schematically shown in Figure 2. Voltmeter and ammeter used were of type HC-300C-S-DV in range of 0-50 V and of type HC-300C-S-DA in range of 1-10A, respectively. A porcelain-type variable resistor $(0-50 \Omega, 150 \mathrm{~W})$ was used as the load.

2) Weather parameter: A solarimeter was used to measure the real-time solar radiation intensity $\left(\mathrm{W} / \mathrm{m}^{2}\right)$. A wind speed sensor (YS-CF-X/S) was used to measure the wind speed.

3) Temperature: Temperatures of the solar panel, ambience, the water flowing in and out the water flume, and the water in the tank was monitored. Some platinum resistances (HT101) and a data acquisition instrument (Agilent 34970A) were used to measure and acquire the realtime temperatures.

The photoelectric conversion efficiency is calculated as:

$$
\eta_{e}=\frac{P}{A_{t} P_{\text {in }}}=\frac{U I}{A_{t} P_{\text {in }}}
$$

where, $\eta_{e}$ is the photoelectric conversion efficiency (\%), $P$ the output power (W), $U$ the voltage (V), $I$ the current (A), $P_{\text {in }}$ the solar radiation intensity $\left(\mathrm{W} / \mathrm{m}^{2}\right), A_{t}$ the total area of solar panel.

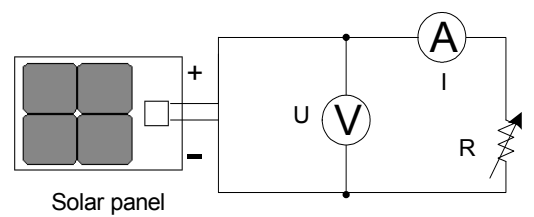

Figure 2. Output characteristics test system of solar panels.

In addition, the solar panels have been encapsulated, so the result calculated by Equation (1) is the photoelectric conversion efficiency of solar panel rather than the net efficiency of the solar cell.

\section{Results and Discussion}

Figures 3-5 show the comparing results between the ordinary solar panel without the heat pipe and solar panel with heat pipe using air-cooling one day in May. The maximal air temperature, the radiation intensity, the maximal and average wind speeds are $36^{\circ} \mathrm{C}, 1001 \mathrm{~W} / \mathrm{m}^{2}$, $5.32 \mathrm{~m} / \mathrm{s}$ and $0.51 \mathrm{~m} / \mathrm{s}$, respectively. The daily net radiation is $26.3 \mathrm{MJ}$ from 5:00 to 19:30.

Figures 6-8 show the comparing results of the solar panel with heat pipe using air-cooling and water-cooling one day in May. The maximal air temperature, the radiation intensity, the maximal and average wind speeds are $35^{\circ} \mathrm{C}$ and $858 \mathrm{~W} / \mathrm{m}^{2}, 4.72 \mathrm{~m} / \mathrm{s}$ and 0.51 $\mathrm{m} / \mathrm{s}$, respectively. The daily net radiation is $21.9 \mathrm{MJ}$ from 5:00 to 19:30.

Figures 3-8 show the peak radiation intensity, power, temperature and photoelectric conversion efficiency from 10:00 to $14: 00$.

Figures 3 and $\mathbf{6}$ show that the radiation intensity is the primary factor affecting the output power of solar panels under a certain load resistance condition. As the solar radiation intensity first increases and then decreases, the output powers of solar panels also decrease after the first increase. The highest points both appear at the same time range between 12:00 to 13:00. The output power of

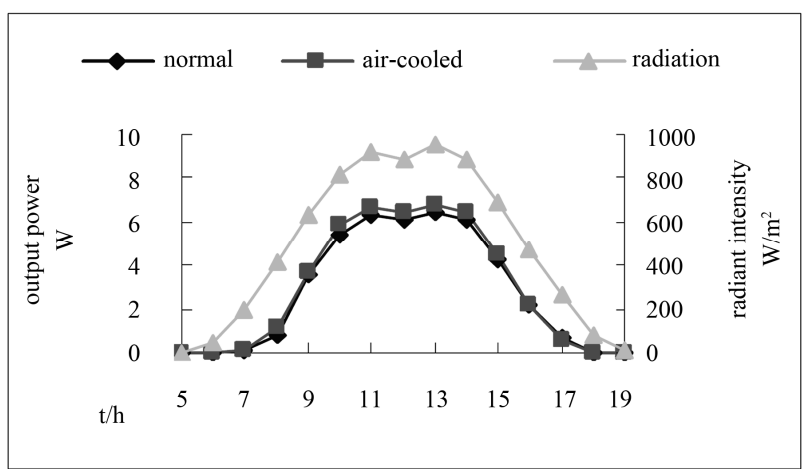

Figure 3. Comparison of hourly output power of solar panel cooling by air with heat pipe and without cooling. 


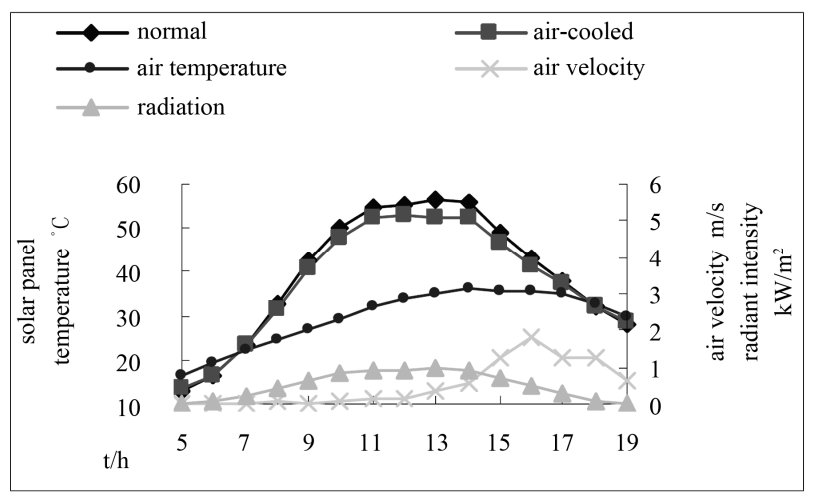

Figure 4. Comparison of hourly temperature of solar panel cooling by air with heat pipe and without cooling.

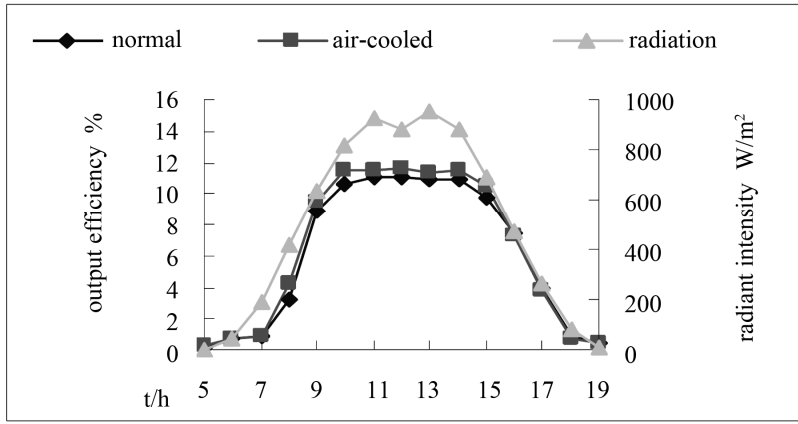

(a)

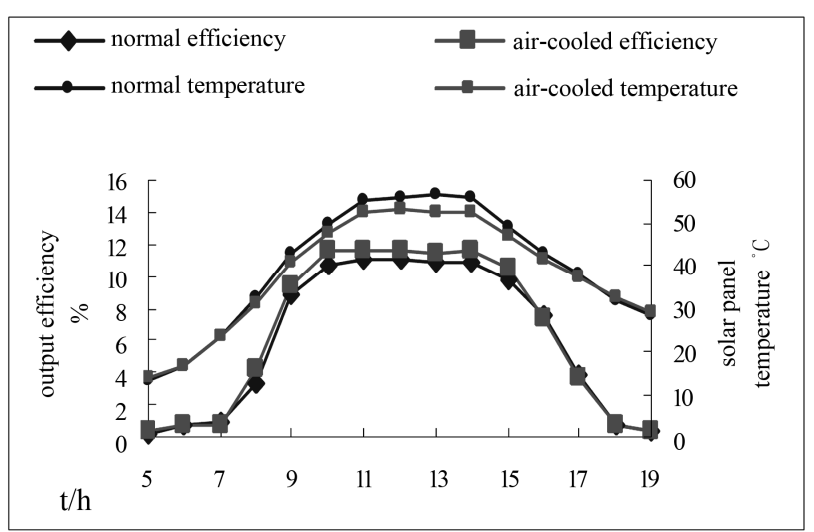

(b)

Figure 5. Comparison of hourly efficiency of solar panel cooling by air with heat pipe and without cooling.

the solar panel with heat pipe using air-cooling increases maximumly by $8.4 \%$ and averagely by $6.3 \%$ compared with ordinary one, as shown in Figure 3. The output power of solar panel with heat pipe using water-cooling increases maximumly by $13.9 \%$ and averagely by $9 \%$ compared with that using air-cooling, as shown in Figure 6.

Figures 4 and 7 show that the radiation intensity, air temperature and wind speed are the main factors affecting the temperature of the solar panel. As the solar radiation

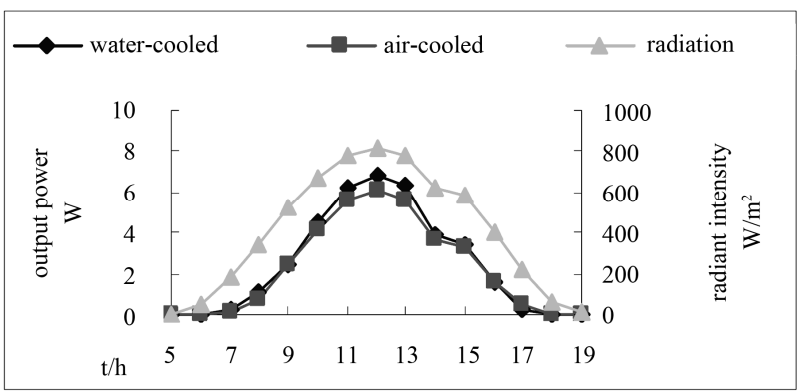

Figure 6. Comparison of hourly output power of solar panel cooling by air with heat pipe and by water with heat pipe.

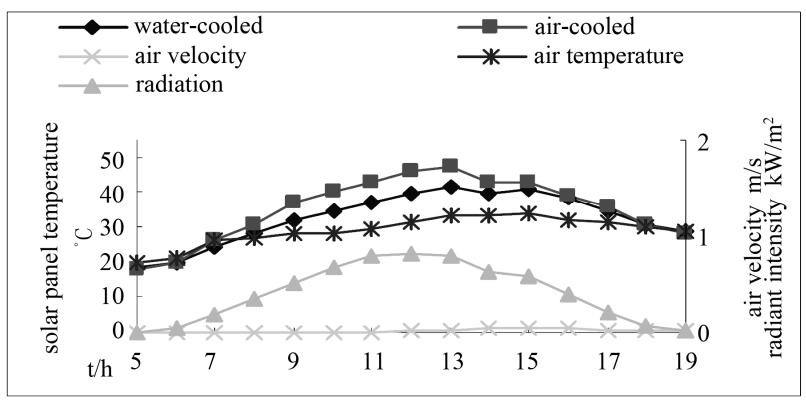

Figure 7. Comparison of hourly temperature of solar panel cooling by air with heat pipe and by water with heat pipe.

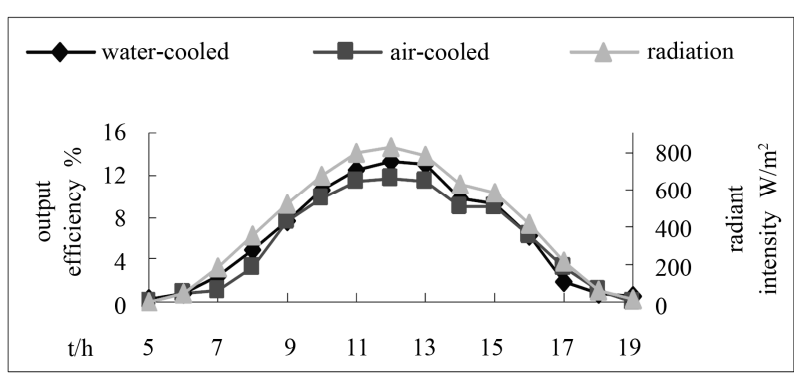

(a)

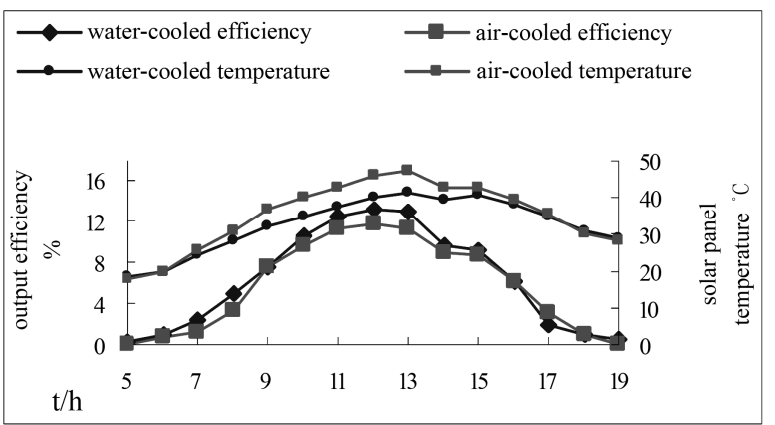

(b)

Figure 8. Comparison of hourly efficiency of solar panel cooling by air with heat pipe and by water with heat pipe.

intensity first increases and then decreases, at the meanwhile, the temperature of the solar panel also decreases after the first increase with a little lag. The maximum 
temperature point appears at the time between 13:00 to 14:00. The temperature of solar panel with heat pipe using air-cooling reduces maximally by $4.7^{\circ} \mathrm{C}$ and averagely by $1.5^{\circ} \mathrm{C}$ corresponds to the reduction of the photoelectric conversion efficiency by $0.2 \%$, from $10: 00$ to 15:00 compared with ordinary one, as shown in Figure 4. The temperature of the solar panel with heat pipe using water-cooling reduces maximally by $8^{\circ} \mathrm{C}$ and averagely by $2.7^{\circ} \mathrm{C}$ compared with that using air-cooling, as shown in Figure 7.

Figures 5 and $\mathbf{8}$ show that the radiation intensity and the temperature of the solar panel are the main factors that affecting the photoelectric conversion efficiency of solar panel. According to the data, the temperature increase of $1 \mathrm{~K}$, the efficiency of solar panel with heat pipe using air-cooling increases maximally by $2.6 \%$ and averagely by $0.4 \%$ compared with ordinary one, as shown in Figure 5. The temperature of solar panel with heat pipe using water-cooling increases maximally by $3 \%$ and averagely by $0.5 \%$ compared with that using air-cooling. The maximum efficiency of $13.5 \%$ can be achieved, as shown in Figure 8.

\section{Conclusions}

A novel micro heat pipe array is used for solar panel cooling. Air-cooling and water-cooling methods used are compared in this study. The results indicate that under cooling condition, the temperature can be reduced to effectively increase the photoelectric conversion efficiency of solar panel.

1) Compared with the ordinary solar panel, the temperature of that using air-cooling reduces maximally by $4.7^{\circ} \mathrm{C}$, the output power increases maximally by $8.4 \%$, and the efficiency difference is $2.6 \%$ (In that day, the maximal air temperature and wind speed are $36^{\circ} \mathrm{C}$ and $5.32 \mathrm{~m} / \mathrm{s}$, the daily global radiation is $26.3 \mathrm{MJ}$ ).

2) Compared with the solar panel using air-cooling, the temperature of that using water-cooling reduces maximally by $8^{\circ} \mathrm{C}$, the output power increases maximally by $13.9 \%$ and the efficiency difference is $3 \%$. The maximum efficiency of $13.5 \%$ can be achieved (In that day, the maximal air temperature and wind speed are $35^{\circ} \mathrm{C}$ and $4.72 \mathrm{~m} / \mathrm{s}$, the daily global radiation is $21.9 \mathrm{MJ}$ ).

\section{References}

[1] W. He, T. T. Chow, J. Ji, et al., "Hybrid Photovoltaic and Thermal Solar-Collector Designed for Natural Circulation of Water," Applied Energy, Vol. 83, No. 3, 2006, pp. 199-220.

[2] Z. J. Weng and H. H. Yang, "Primary Analysis on Cooling Technology of Solar Cells under Concentrated Illumination," Energy Technology, Vol. 29, No. 1, 2008, pp. 16-18.

[3] K Araki, H Uozumi and M Yamaguchi, "A Simple Passive Cooling Structure and its Heat Analysis for $500 \times$ Concentrator PV Module," 29th IEEE PVSC, New Orleans, May 2002, pp. 1568-1571.

[4] M. Brogren and B. Karlsson, "Low-Concentrating-Water Cooled PV-Thermal Hybrid Systems for High Latitudes," 29th IEEE PVSC, New Orleans, May 2002, pp. 17331736.

[5] M. A. Farahat, "Improvement the Thermal Electric Performance of a Photovoltaic Cells by Cooling and Concentration Techniques," 39th UPEC International, Bristol, Vol. 2, 2004, pp. 623-628.

[6] A. Akbarzadeh and T. Wadowski, "Heat Pipe-Based Cooling Systems for Photovoltaic Cells under Concentrated solar Radiation," Applied Thermal Engineering, Vol. 116, No. 1, 1996, pp. 81-87.

[7] W. G. Anderson, P. M. Dussinger, D. B. Sarraf and S. Tamanna, "Heat Pipe Cooling of Concentrating Photovoltaic Cells," 33rd IEEE Photovoltaic Specialists Conference, San Diego, May 2008, pp. 1-6.

[8] Y. H. Zhao, et al., "A Sort of Micro Heat Pipe Array and Processing Technics," Chinese Patent: 200810225649.

[9] Y. H. Zhao, et al., "Photovoltaic Cells Radiating Equipment," Chinese Patent: 200810239002.0.

[10] H. Liu, D. C. Wu, Z. G. Yang and Y. H. Zhai, "Household Photovoltaic Power System," Chemical Industry Press, Beijing, 2007.

[11] Z. H. Zhang, L. L. Li, C. P. Ye and P. H. Yang, "Organic Solar Cells and Plastic Solar Cells," Chemical Industry Press, Beijing, 2007. 